Jurdimas (Jurnal Pengabdian Kepada Masyarakat) Royal

Vol. 2 No. 2, Juli 2019, hlm. 127 - 132

ISSN 2614-7912 (Print)

DOI: https://doi.org/10.33330/jurdimas.v2i2.334

ISSN 2622-3813 (Online)

Available online at https://jurnal.stmikroyal.ac.id/index.php/jurdimas

\title{
PELATIHAN E-LEARNING PADA GURU SMA IT PLUS BAZMA BRILLIANT
}

\author{
Nur Budi Nugraha ${ }^{1^{*}}$, Ari Sellyana ${ }^{1}$, Mustazzihim Suhaidi ${ }^{1}$ \\ ${ }^{1}$ Program Studi Teknik Informatika, Sekolah Tinggi Teknologi Dumai \\ email:*nurbudinugroho87@gmail.com
}

\begin{abstract}
Along development process of teaching activities in classroom has many challenges and demands. The increasing number information channels that can be accessed by students so that teacher often lags far behind the updated information that has been received. Therefore teacher is forced to compensate by looking for various additional information. One of the learning strategies that has not been widely applied today is the e-learning strategy. Edmodo is a paid e-learning website that can be utilized teachers implementing learning strategies. But there are still many teachers who do not know and utilize it to fullest helping learning process in the classroom. The method used this training is lecture, discussion and direct practice. The lecture method and discussion are used to convey information relating the theories and benefits of applying edmodo. With direct practice, teachers will be more understanding in applying edmodo. It is expected that after this training, teachers are able compile learning materials in e-learning online so that teachers are not only fixated on conventional learning models. After that, the teacher can implement e-learning in the class he is teaching. Starting from listening material, making assignments given through assignments and online quizzes for the subjects they teach.
\end{abstract}

Keywords: Learning Strategy, e-Learning, Edmodo

\begin{abstract}
Abstrak: Seiring perkembangan zaman proses kegiatan mengajar di kelas memiliki banyak tantangan dan tuntutan. Semakin banyaknya jalur informasi yang dapat diakses oleh siswa sehingga tidak jarang guru tertinggal jauh dari updatenya informasi yang sudah diterima oleh siswa. Oleh karena itu guru dipaksa harus mengimbanginya dengan mencari berbagai informasi tambahan. Salah satu strategi belajar yang belum banyak diterapkan saat ini adalah strategi belajar e-learning. Edmodo merupakan website e-learning tidak berbayar yang dapat dimanfaatkan oleh guru dalam menerapkan strategi belajar e-learning. Namun masih banyak guru yang belum mengetahui dan memanfaatkannya secara maksimal dalam membantu proses belajar mengajar di kelas. Metode yang digunakan dalam pelatihan ini yaitu ceramah, diskusi dan praktek langsung. Metode ceramah dan diskusi digunakan untuk menyampaikan informasi yang berkaitan dengan teori-teori dan manfaat menerapkan edmodo. Dengan praktek langsung, guru-guru akan lebih memahami dalam menerapkan edmodo. Diharapkan setelah diadakan pelatihan ini, guru-guru SMA IT Plus Bazma Brilliant mampu menyusun materi pembelajaran secara e-learning online sehingga guru tidak hanya terpaku pada model pembelajaran konvensional saja. Setelah itu, guru dapat mengimplementasikan pembelajaran e-learning di dalam kelas yang diampunya. Mulai dari menguploud materi, membuat tugas yang diberikan melalui fitur assignment dan kuis online untuk mata pelajaran yang diajarnya.
\end{abstract}

Kata kunci: Strategi Belajar, e-Learning, Edmodo 
Available online at https://jurnal.stmikroyal.ac.id/index.php/jurdimas

\section{PENDAHULUAN}

Seiring perkembangan zaman proses kegiatan belajar mengajar di kelas kini sudah memiliki banyak tantangan dan tuntutan. Salah satunya adalah semakin banyaknya jalur informasi yang dapat diakses oleh siswa hingga terkadang tidak jarang guru tertinggal jauh dari update-nya informasi yangs udah diterima oleh siswa. Oleh karena itu guru pun seolah-olah dipaksa harus mengimbanginya dengan mencari berbagai informasi tambahan menggunakan berbagai media seperti akses internet dan buku refrensi terbaru dan up to date. Selain terkait dengan konten materi pembelajaran, saat ini juga telah muncul berbagai macam alternatif strategi belajar mengajar yang dapat diterapkan oleh guru, sehingga guru tidak hanya terpaku pada satu model pembelajaran saja. Mulai dari yang menggunakan metode konvensional hingga mengarah pada penggunaan media yang tergolong sangat maju. Media pembelajaran elektronik merupakan perangkat penting yang dapat digunakan oleh untuk meningkatkannya motivasi dan pendidikan siswa (Mateo, Rey, \& Hernández, 2010).

Salah satu strategi belajar yang belum banyak diterapkan saat ini adalah strategi belajar e-learning. Salah satu definisi umum dari e-learning diberikan Surjono (2013), yaitu: pengiriman materi pembelajaran melalui suatu media elektronik seperti internet, intranet/extranet, satellite broadcast, audio/video tape, interactive TV, CDROM, dan computer-based training (CBT). Menurut Khan (2014), e-learning menunjuk pada pengiriman materi pembelajaran kepada siapapun, dimanapun, dan kapanpun dengan menggunakan berbagai teknologi dalam lingkungan pembelajaran yang terbuka, fleksibel dan terdistribusi. Lebih jauh, istilah pembelajaran terbuka dan fleksibel merujuk pada kebebasan peserta didik dalam hal waktu, tempat, kecepatan, isi materi, gaya belajar, jenis evaluasi, belajar kolaborasi atau mandiri (Hourdequin, 2014). Dengan E-Learning, peserta ajar (murid) tidak perlu duduk dengan manis di ruang kelas untuk menyimak setiap ucapan dari seorang guru secara langsung.

E-Learning belum banyak diterapkan oleh guru karena kebanyakan guru menganggap strategi ini membutuhkan sarana dan prasarana yang cukup mahal dan kebanyakan sekolah belum fasilitas yang dianggap mendukung. Padahal pada kenyataannya, e-learning tidak harus menggunakan fasilitas yangtergolong mahal dan harus memiliki website e-learning sendiri. Saat ini sudah banyak website e-learning yang bersifat free access dan tidak berjangka waktu. Masalah ini juga dipertegas oleh Suhartanto (2010) yang merincikan tentang beberapa faktor yang mendukung e-learning sudah cukup layak untukdipakai di sekolah Indonesia : 1) Siswa tingkat SMP dan SMA sudah sangat pandai memanfaatkan TIK dalam aktifitas sehari-hari. 2) Banyak sekolah telah memiliki perangkat komputer, namun hanya digunakan sebagai perangkat administrasi saja. 3) Telah tersedianya beberapa sistem pendukung elearning, bahkan sudah banyak yang tersedia dalam bentuk open source atau juga yang gratis seperti Moodle.

Terkait dengan beberapa faktor di atas, salah satu akses website e-learning yang dapat dimanfaatkan secara tidak berbayar adalah Edmodo. Menurut Zwang (2010), “edmodo adalah sebuah situs pendidikan berbasis social networking yang di dalamnya terdapat berbagai 
Available online at https://jurnal.stmikroyal.ac.id/index.php/jurdimas

konten untuk pendidikan. Edmodo merupakan social network berbasis lingkungan sekolah (school based environment) yang dikembangkan oleh Nicolas Borg and Jeff O'Hara, dengan fitur-fitur pendukung proses belajar mengajar $(\mathrm{Nu}-$ rita, 2011). Fitur utama edmodo adalah dukungan aktif terhadap model komunikasi dari sosial media online, yang ditambahkan dengan fitur online learning material dan online evaluation. Meskipun Edmodo memiliki fitur-fitur yang hampir sama dengan facebook, dari segi kerahasiaan Edmodo lebih bersifat privasi.

Edmodo juga sebagai website $e$ learning tidak berbayar yang dapat dimanfaatkan oleh guru untuk menjadi salah satu media dalam menerapkan strategi belajare-learning. Namun saat ini belum banyak guru-guru yang mengetahui akan adanya media ini dan ataupun memanfaatkannya secara maksimal dalam membantu proses belajar mengajar di kelas. Kelebihan dari media website ini adalah media ini tidak hanya dapat diakses melalui media laptop saja, namun Edmodo ini juga sudah tersedi dan bisa diakses dalam bentuk aplikasi android. Hal ini bisa mempermudah guru dalam memantau kinerja dan interaksi antara guru dan siswa melalui smartphone maupun gadget berbasis android lainnya.

Hikmah (2017) menjelaskan bahwa edmodo platform pembelajaran sosial untuk guru, siswa dan orang tua. Guru juga mampu memposting nilai, tugas dan kuis kepada siswa. Penerapan strategi belajar e-learning ini juga dapat membantu guru untuk menggantikan proses belajar mengajar yang ada di kelas dan dibawa menjadi interaksi dalam dunia maya melalui website elearning Edmodo ini pada siswa. Sehingga tidak ada alasan lagi bagi siswa akan tidak PEMBAHASAN memiliki aktifitas dikelas ketika guru memiliki kesibukan atau acara di luar kelas pada saat jam pelajaran.

\section{METODE}

Metode yang digunakan dalam kegiatan pelatihan ini yaitu ceramah dan diskusi, bimbingan dan pelatihan. Metode ceramah dan diskusi digunakan untuk menyampaikan informasi yang berkaitan dengan Edmodo, teori-teori tentang Edmodo, serta manfaat menerapkan Edmodo. Selama kegiatan ceramah dan diskusi peserta akan dibekali modul pelatihan. Metode bimbingan dan pelatihan digunakan untuk menindak lanjuti dan mematangkan materi yang telah disampaikan dalam ceramah dan diskusi. Dengan praktek langsung, guru-guru akan lebih memahami dalam menerapkan Edmodo.

Target kegiatan pengabdian masyarakat ini adalah untuk meningkat pengetahuan dan keterampilan guru-guru SMA IT Plus Bazma Brilliant dalam memanfaatkan dan mengembangkan strategi belajar E-learning berbasis website online menggunakan Edmodo. Paradigma evaluasi ketercapaian target kegiatan dapat dilihat pada gambar 1 .

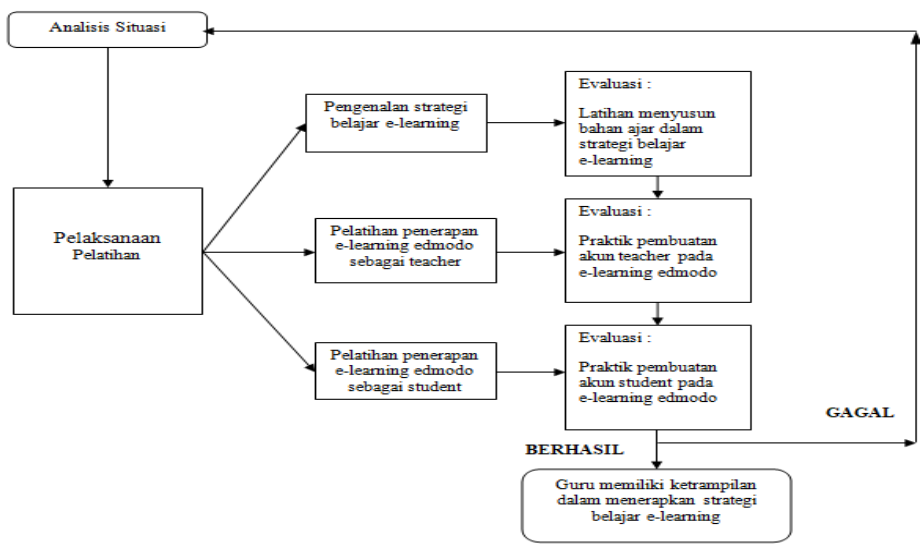

Gambar 1. Rancang Evaluasi 
Available online at https://jurnal.stmikroyal.ac.id/index.php/jurdimas

Pengabdian pada masyarakat ini dilaksanakan pada hari Senin tanggal 31 Januari 2019 di Gedung AULA SMA IT Plus Bazma Brilliant dan dihadiri oleh seluruh majelis guru SMA IT Plus Bazma Brilliant. Pelatihan ini dibuka langsung oleh bapak Sukanto, B.Irk selaku kepala sekolah SMA IT Plus Bazma Brilliant.

Materi pertama disampaikan oleh ibu Ari Sellyana, M.Kom yang membahas tentang pengenalan strategi belajar elearning. Dalam sesi ini dosen memberikan informasi mengenai pemanfaatan e-learning bagi dunia pendidikan, pengenalan dasae aplikasi edmodo, cara mendaftar akun di edmodo (baik sebagai guru atau siswa) hingga pengenalan fitur dan keunggulan edmodo.

Selain memberikan materi, peserta pelatihan juga dibekali dengan modul pelatihan yang dapat digunakan sebagai alat bantu dalam pelatihan e-learning ini.

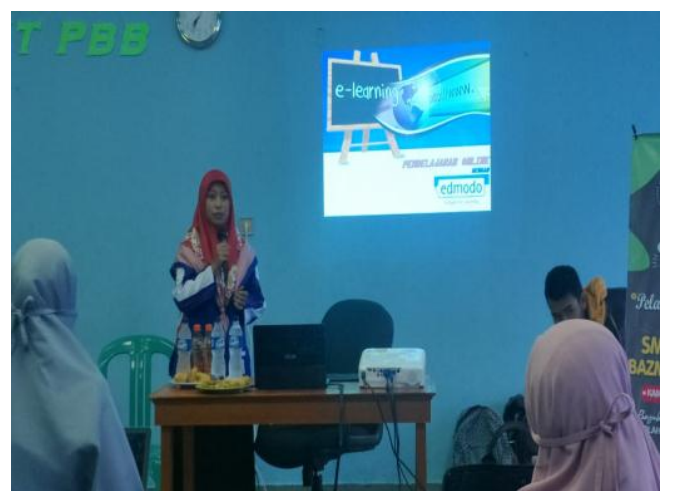

Gambar 2. Penyampaian materi pertama

Materi kedua disampaikan oleh bapak Nur Budi Nugraha, MT. Pada sesi ini dosen memberikan materi yang difokuskan pada pengemasan konten pembelajaran, dilanjutkan dengan praktek pembuatan akun edmodo langsung serta serta simulasi dalam proses pembelajaran. Selama kegiatan praktek, peserta pelatihan dibantu oleh dosen tim pengabdian dalam membuat akun edmodo dan memanfaatkan fitur fitur yang

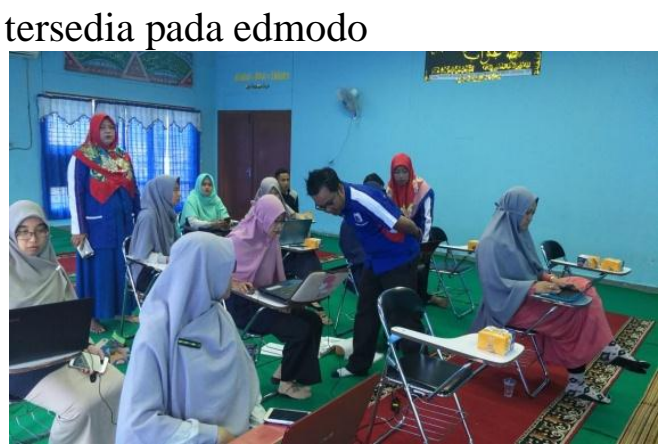

Gambar 3. Praktek langsung pembuatan akun edmodo

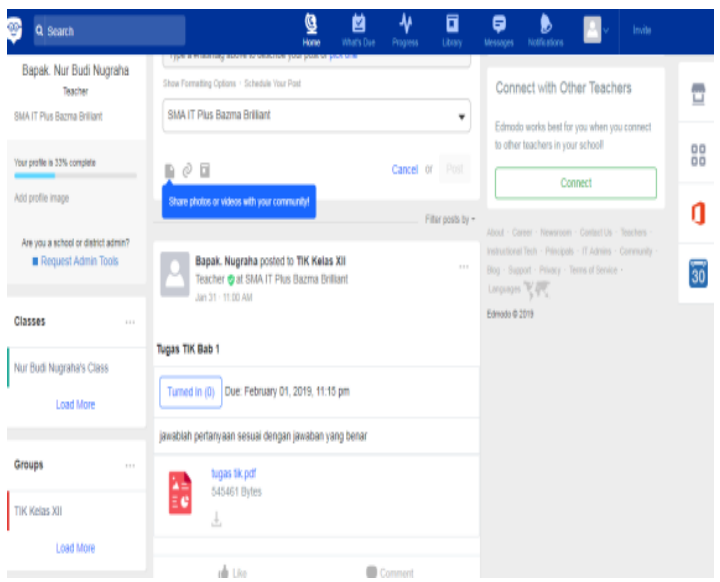

Gambar 4. Tampilan halaman awal edmodo

Secara umum kegiatan pengabdian ini berjalan lancar, dimulai dari kegiatan survei pendahuluan, pelaksanaan kegiatan pengabdian, sampai kepada penyusunan laporan. Berdasarkan diskusi yang diselenggarakan diperoleh kesimpulan bahwa para peserta pengabdian tersebut merasa senang dan puas. Hal ini terbukti dengan adanya permintaan dari para peserta agar kegiatan pengabdian ini tidak hanya diselenggarakan satu kali tetap harus berkelanjutan, mengingat pentingnya pembelajaran dan pengenalan e-learning bagi guru guru SMA IT Plus Bazma Brilliant.

Melalui pengabdian yang berkelanjutan akan terjalin hubungan kerjasama antara Sekolah Tinggi 
Available online at https://jurnal.stmikroyal.ac.id/index.php/jurdimas

Teknologi Dumai dengan Guru Guru SMA IT Plus Bazma Brilliant. Hubungan kerjasama dalam hal pengembangan metode pembelajaran bagi guru guru SMA IT Plus Bazma Brilliant sehingga program pengabdian masyarakat dapat berjalan maksimal yang menjadi salah satu kewajiban dosen Sekolah Tinggi Teknologi Dumai. Tingginya antusiasme peserta ditandai dengan banyaknya pertanyaan dan tingginya perhatian dari peserta sejak pengabdian dimulai hingga berakhir. Peserta pengabdian juga meminta agar pelatihan e-learning dapat dilanjutkan pada tahun mendatang dan disediakan kesempatan bagi para peserta untuk konsultasi lebih mendalam untuk semua materi pelatihan.

Faktor-faktor yang mendukung pelaksanaan pengabdian sehingga dapat terlaksana dengan lancar adalah Tingginya antusiasme peserta pengabdian Guru Guru SMA IT Plus Bazma Brilliant untuk mengikuti pelatihan e-learning, Manfaat yang besar atas tema pengabdian mengenai metode pembelajaran elearning bagi Guru Guru SMA IT Plus Bazma Brilliant dan Fasilitas dan semangat tim pengabdi yang mendukung kelancaran pengabdian. Selain faktor pendukung, ada pula faktor penghambat yang mengakibatkan kegiatan pengabdian ini tidak mampu mencapai tujuan secara maksimal, yaitu waktu pengabdian hanya setengah hari dan singkat mengakibatkan peserta masih banyak ingin mendalami tentang e-learning Edmodo kurang maksimal dan Koordinasi antar perserta pegabdian yaitu guru-guru SMA IT Plus Bazma Billiant belum bisa berjalan dengan sempurna karena perbedaan kegiatan dan kepentingan masingmasing untuk memiliki hari yang sama untuk mengikuti kegiatanpengabdian.
Hasil yang diperoleh dari pengabdian ini adalah sebagai berikut :

1. Peserta yang hadir pada acara pengabdian itu sejumlah 19 orang dari 25 orang yang diundang. Alasan ketidakhadiran beberapa orang peserta tersebut adalah karena memiliki kegiatan lain dengan jadwal yang bersamaan dengan jadwal pengabdian.

2. Materi yang diberikan pada pengabdian ini meliputi materi Strategi Belajar Mengajar dan Pengenalan E-Learning, Penerapan E-Learning sebagai Teacher dan Penerapan E-Learning sebagai Student.

Tabel 1. Jumlah Peserta PPM

\begin{tabular}{|c|c|c|c|}
\hline No & Jenis Kelamin & Jumlah & Persentase \\
\hline 1 & Laki-Laki & 9 & $47,37 \%$ \\
\hline 2 & Perempuan & 10 & $52,63 \%$ \\
\hline & Total & 19 & $100 \%$ \\
\hline
\end{tabular}

3. Para peserta yang mengikuti pelatihan merasa senang dan puas dengan kegiatan pengabdian ini, hal ini terlihat dari ungkapan kepuasan serta keantusiasan peserta mendengarkan dan bertanya berbagai hal tentang materi yang telah diberikan oleh para pengabdi.

4. Kegiatan pengabdian ini dianggap oleh peserta sebagai sarana pengenalan dan pembelajaran mengenai e-learning dan platformnya, dan penyiapan materielearning.

5. Pada acara penutupan, hampir seluruh para peserta mengharapkan agar program serupa diadakan kembali untuk lebih memahami 
Available online at https://jurnal.stmikroyal.ac.id/index.php/jurdimas

mengenai e-learning dan penerapan dalam Edmodo.

\section{SIMPULAN}

Berdasarkan uraian pelaksanaan kegiatan pengabdian ini, dapat disimpulkan bahwa partisipasi peserta pengabdian sebesar $90 \%$ mengingat dari 25 calon peserta yang diundang yang hadir 19 orang. Peserta aktif bertanya dan mendengarkan berbagai hal tentang materi yang telah diberikan sampai kegiatan pelatihan $e$ learning berakhir. Para peserta merasa memperoleh wawasan baru tentang penggunaan e-learning dalam proses belajar mengajar, terlebih lagi e-learning dapat menjadi alternative pengganti pros-

\section{DAFTAR PUSTAKA}

Hikmah, A.N.2017. Efektivitas Media pembelajaran Edmodo Terhadap Minat Belajar dan Hasil Belajar Siswa pada Materi Fisika Kelas XI IPA SMAN 1 Tanete Rilau. Skripsi. Makassar: Fakultas Keguruan dan Tarbiyah Universitas Negeri Islam Alauddin Makassar.

Hourdequin, P. 2014. Edmodo: A Simple Tool for Blended Learning. The Language Teacher38

Khan, D.D., 2014.Pengembangan ELearning Teori dan Desain. PT. Remaja Rosdakarya: Bandung

Mateo, Rey, P. d., \& Hernández. 2010. Student motivation and crosscurricular development through elearning applied to cooperation. The Future of Global Learning Engineering Education (EDUCON). es pembelajaran yang tidak dapat diselenggarakan dikelas.

\section{UCAPAN TERIMA KASIH}

Penulis mengucapkan terima
kasih kepada Ketua Sekolah Tinggi Tinggi Dumai dan Ketua Lembaga Penelitian dan Pengabdian Kepada Masyarakat Sekolah Tinggi Tinggi Dumai yang telah memberikan bantuan dana dalam penyelenggaraan pengabdian masyarakat ini. Selain itu, penulis juga mengucapkan terima kasih kepada panitia dan peserta pelatihan sehingga acara ini dapat terlaksana dengan baik dan lancar.

Nurita, P. 2013. Cara Membuat Media Pembelajaran Online Menggunakan Edmodo.Jurnal Pendidikan Informatika dan Sains, 2(2).

Suhartanto, H., 2010. Strategi Implementasi Sistem E-Learning untuk Peningkatan Mutu Pendidikan, Jurnal Insand Comtech 1(1): 2731.

Surjono, D. H. 2013. Membangun Course E-Learning Berbasis Moddle Edisi Kedua, UNY Press.

Zwang, J. (2010). Edmodo:A Free, Secure, Social Networking Site For School. (Online),

http://www.eschoolnews.com/2010/12/15 /edmodo-a-free-secure-social networkingsitefor-school/. Diakses 8 Februari 2019 